\title{
A Survey on Ontology-Based Systems to Support the Prospection, Diagnosis and Treatment of Breast Cancer
}

\author{
Cassia Isac \\ Rio de Janeiro Federal Institute \\ Paracambi, RJ. Brazil \\ $+55-21-26295479$ \\ cassia.goncalves@ifrj.edu.br
}

\author{
José Viterbo \\ Fluminense Federal University \\ Niteroi, RJ. Brazil \\ +55-21-2629 5479 \\ viterbo@ic.uff.br
}

\author{
Aura Conci \\ Fluminense Federal University \\ Niteroi, RJ. Brazil \\ +55-21-2629 5479 \\ aconci@ic.uff.br
}

\begin{abstract}
In a scenario where there is a huge amount of available data sources, the Semantic Web has played a key role in sharing, retrieval, selection, and combination of data organized in various formats. The storage and retrieval of medical images manipulated by systems that support breast cancer detection can take great advantage from the use of such technology. In this paper we present a comprehensive study on ontology-based systems that support the manipulation of medical images related to breast cancer, identifying the main features of each approach.
\end{abstract}

\section{Categories and Subject Descriptors}

H.3.5 [Artificial Intelligence]: Knowledge Representation Formalisms and Methods - Ontologies; J.3 [Life and Medical Sciences]: Medical information systems

\section{General Terms}

Standardization.

\section{Keywords}

Ontology; Breast cancer; Medical Image; Medical System

\section{INTRODUCTION}

Breast cancer is the second most common type of cancer in the world and - except for skin cancer - it is the most common type among women. Although breast cancer affects both men and women, on average, the parcel of affected men is limited to $1 \%$ of the total number of cases. According to the American Cancer Society [10], in 2014 about 40,000 women will die from breast cancer in the United States. One of the main factors that increase the number of deaths is the late diagnosis, i.e., upon detection, cancer is in already advanced stages and treatment is ineffective.
Permission to make digital or hard copies of all or part of this work for personal or classroom use is granted without fee provided that copies are not made or distributed for profit or commercial advantage and that copies bear this notice and the full citation on the first page. To copy otherwise, or republish, to post on servers or to redistribute to lists, requires prior specific permission and/or a fee. SBSI 2016, May 17-20, 2016, Florianópolis, Santa Catarina, Brazil. Copyright SBC 2016.
While mammography and ultrasonography are the most used exams in the diagnosis of this pathology, the first one is far more effective for detecting breast cancer in woman after menopause. Although breast ultrasound is good at distinguishing between a fluid-filled cyst and a solid mass, it cannot provide images of the entire breast at once. Therefore, ultrasonography is used for a punctual check of areas that a screening mammogram has already revealed. Moreover, it cannot show microcalcifications (the most common feature of tissue about tumor [10].

Nevertheless, researches shows that exposure to radiation can increase up to five times the chances of young women with a mutation in the BRCA1 and BRCA2 genes developing the disease [2], [26]. Moreover, although mammography is currently regarded as the "gold standard" technology for the diagnosis of breast cancer, the performance of this procedure is not always good for young women, due to the difficulty of imaging dense breast [5] Consequently, despite the comparative success of mammography, there is a need for more researches to increase sensitivity of breast cancer detection, especially in younger women [23].

According to INCA (the Brazilian Cancer Institute) [23] other issue that increases the number of deaths is related to false negative results due to poor interpretation of medical images. The organization mentioned that around $60 \%$ of the exams, coming from both public health system or private clinics, present problems that defy the interpretation of medical images.

The interpretation of a medical image involves the identification of the image area, existence of abnormality or lesions, etc. Each medical image contains extensive information about anatomy and abnormal structures. Moreover, the person that examines it must know how the prospected diseases develop. For example, researchers may want to indicate where in certain areas of interest abnormalities are present. This information is often considered "image meta data", and includes image comments, interpretations, and conclusions. Once abnormalities are identified, a diagnosis may be issued. Many works [36], [8], [20] and [9] perform their classifications according to BIRADS (Breast Imaging Reporting and Data System) classification, elaborated by ACR (American College of Radiology).

Thus, emerges the need for the use of computational tools that can describe singular characteristics of existing abnormalities, allowing the cataloging of these images according to its pathological type. Furthermore, it is necessary to use large amounts of information (database, record the patient data) and the manipulation of this information (such as images and data recoveries) in order to classify a new case based on a possible diagnostic that occurred previously with other patients.

Semantic Web is a web extension that adds semantic or "meaning"' to the current format of data representation. Hence, 
the use of Semantic Web technologies may play a fundamental role in the organization and manipulation of very large knowledge bases. In such scope, several technologies were proposed, such as the use of ontology aiming to assign semantics, i.e., specific meaning to the content of documents, acting as a knowledge representation tool [30].

In the medical domain, ontology-based systems may be used to support healthcare professionals in several ways, by helping them to store, manage, and retrieve information as well as to do interpretation and annotation (i.e. to emphasize the region of interest, making pertinent descriptions for these locations) on medical images. For example, a professional that wants to classify a new image based on their semantic description can retrieve some similar case in a database and establish a relationship between both studied and retrieval cases.

This paper presents a study about ontology-based systems that support the manipulation of medical images related to breast cancer. By highlighting the benefits brought by the use of ontologies to this application domain, we intend to discuss how Semantic Web technologies can be integrated into ontolgybased systems to support the prospection, diagnosis and treatment of breast cancer. This study is part of the VisualLab Project [44], a project from Fluminense Federal University that seeks to diagnose breast diseases based on thermogram images.

Thus, we present a review about the literature on related works, in which we do not compare the ontologies themselves, but we rather promote a comprehensive study of the systems where this technology is applied, identifying the main features of each approach. This paper is organized as follows: next section considers the medical ontology in general. Section 3 presents an overview of systems, frameworks, and tools that use ontology as basis. Our discussion and conclusion are in the Sections 4 and 5 .

\section{ONTOLOGIES IN THE MEDICAL FIELD}

The advances of the computer technology brought an accumulation of medical information for diagnostic and health treatment purposes. Consequently, large amounts of medical information must be stored and managed on information systems. Data types are diverse ranging from patients' names, age, and sex up to descriptions of certain diagnostic reports to complete medical cases that can be acquired in for long periods of time. Moreover, medical information is not limited to text documents. Advances in imaging technology have dramatically increased the amount of medical image generated daily by hospitals, clinics, pharmaceutical companies, and academic research centers.

In this context, ontologies have become a powerful computational tool to manage the huge amount of information stored in databases or available on the Internet. Ontologies are computational artifacts designed to provide representations of a domain of interest [30], providing a vocabulary for representing the knowledge and for describing specific situations in such domain. The main benefits of this sort of model are (a) enabling the reuse of models, (b) enabling the sharing of common knowledge among several applications [45] and (c) allowing the use of formal analysis of the domain knowledge, such as performing reasoning to provide diagnosis [34]

Ontologies bring the necessary standardization in the medical domain, offering a range of options to record observations and events encountered by medical professionals [37]. Ontologies can also be used to describe a medical image at different levels of detail. They can describe simple information such as date, type of capture or even more complex information, allowing inferences about diseases, supporting diagnostic tools.

Several ontologies were made for the medical domain like: Systematized Nomenclature of Medicine Clinical Terms (SNOMED CT [38], Gene Ontology (GO) [40], Foundational Model of Anatomy (FMA) [32], BreastCancerOnto [42][7], Breast Cancer Imaging Ontology (BCIO) [42][7], Unified Medical Language System (UMLS) [4] and others. Some of them will be discussed ahead, in the scope of this work.

\section{LITERATURE REVIEW}

Several ontologies have been developed in order to structure the knowledge in the medical domain, particularly in the medical imaging field. Many of them have became a widely used in different works. In a literature review we found several systems that use ontologies as tools to assist health professionals with issues related to breast cancer such as information retrieval, searching, classification, interpretation, annotation, and others. To show the relevance of this technology to support the diagnosis of breast cancer, in the next subsections we present 6 works related to 5 different ontologies. It should be emphasized that our intention is not making a sheer comparison among those systems, but rather to highlight the peculiarities, advantages and disadvantages of each approach in its respective application.

\subsection{Medical Imaging and Advanced Knowledge Technologies - MIAKT}

MIAKT (Medical Imaging and Advanced Knowledge Technologies) project [14] is a joint initiative between AKT (Advanced Knowledge Technologies) and IRC, (Medical Images and Signals). MIAKT [36] provides knowledge management for the data that the screening process generates, offering a means for medical staff to investigate, annotate, and analyze such data using web applications. The application software allows the viewing and annotation of various types of images, from X-ray mammograms to 3-dimensional magnetic resonance imaging (MRI) scans, allowing the search for patient data and supporting the invocation of services on the web for image analysis and data analysis [13].

The ontology developed in this project was called the Breast Cancer Imaging Ontology (BCIO). It was structured as a set of simple subsumption relationships to aid in both reusability and reasoning. This ontology is based on a standardized BIRADS lexicon and covers both exams (mammography and MRI). Another part of BCIO is the set of terms related to medical tests, such as radiological findings, medical exams, medicaldescriptor. It also captures images metadata, for instance, registering whether an X-ray is of the left $(\mathrm{L})$ or right $(\mathrm{R})$ breast, and from Cranio Caudal (CC) or Medium Lateral Oblique View (MLO) position; information of vital importance in locating lesions of tumors [14]

One of the MIAKT functionalities is to classify a cancer as malignant or benign. For this purpose, it is applies classifiers like Naive Bayes and Linear classifier. All the classifiers give correct classification in $75 \%$ of the cases. The authors of [13] emphasize that classification accuracy is limited by the data source and they are investigating more fully-annotated patient cases for achieving better classifications. Nevertheless, the system has a good performance in other tasks proposed.

\subsection{Aquest}

Aquest proposes an education oriented ontology-based system to assist students in the interpretation of mammograms and 
diagnosis of breast cancer [3]. It implements a question and answer web service that answers questions such as, "how to classify a lesion associated with lobular form?"; "what kinds of micro-calcifications are related to malignant neoplasm?"; "what are the categories of BIRADS associated with circumscribed margins?"; "what radiographic findings are associated with circumscribed margins?"; "what radiographic findings are associated with obscured margins?" or "What are the radiological findings partially associated with benign neoplasm?".

Aquest is based on the BreastCancerOnto, an ontology that represents the medical knowledge about radiological findings on mammograms. The application domain involves the interpretation and analysis of mammograms to aid the diagnosis of breast cancer, for educational purposes. The creation of BrestCancerOnto consisted in five steps, according to [42] determination of application domain, construction of the lexicon; mapping and lexicon-ontology; construction of ontology; and finally the implementation of the ontology. Aquest is a module of the next system presented here, called INDIAM [19], built to make a consultation in BreastCancerOnto and integrated to a breast cancer tutorial that allows users to access the Internet to obtain more information on the topic being researched.

\subsection{Interpretation and Diagnosis of Mammograms - INDIAM}

INDIAM [19], is an interpretation and diagnosis system, developed to train students for interpretation of mammograms. The proposed system is composed of four principal modules: Search web service, Aquest web service, Diagnosis-Tutor web service, and Diagnosis-Simulation web service interface. INDIAM is integrated with an Indexed Atlas of Digital Mammograms (AMDI), which is an atlas available via Web that also includes a research system to retrieve images based on content and a tool for inserting new mammographic cases by registered radiologists.

The Search web service finds the semantics of the term entered by the user in the BrestCancerOnto ontology and submits a query with a better defined semantics for the Google and Yahoo services. This service ensures more robust queries, less subject to false positive. The Diagnosis-Simulation module was created to guide doctors, students, and researchers to relate the existing knowledge on the breast cancer field, such as analysis and diagnosis of breast cancer using cases retrieved from a mammographic database.

The Diagnosis-Tutor module consists in a web service to train students for interpretation of mammograms. The information of each case stored in the mammographic database includes radiological findings, clinical history, lifestyle of patient, and complementary exams. It is important to highlight that INDIAM system also uses the BreastCancerOnto (used in Aquest) for representing information content in X-ray image about radiological findings and classifies them according to BIRADS categories.

\subsection{Mammography Annotation Tool - MAT}

Bulu at al, [8] presented a new Mammography Annotation Tool (MAT) and ontology-based annotation and retrieval system for breast masses with description of high and mid-level features. This system consists to allows that a radiologist get access a mammography image and from its visualization can make annotation about existing abnormalities in images. All parts of the annotation are stored in an RDF file as concept instances.
Then, SQWRL (Semantic Query-Enhanced Web Rule Language) is used to retrieve breast masses examined in digital mammography.

Mammography Annotation Ontology (MAO) is developed in [8] as well. MAO is based on the 3rd edition of BIRADS Mammography Atlas (American College of Radiology, 2012). This ontology was used to annotate any abnormality observed in mammograms. The tool MAT allows radiologists to examine the four images of a mammogram: CC and MLO projection of the right and left breasts, respectively. The radiologists mark and annotate the abnormalities identified in the images by using a variety of tools and can also add the breast type [8]. Image search, i.e., the recovery of similar cases in the database, is performed based on the proximity between the characteristics (mass) found in the views of mammograms. The author emphasizes that time performance of this system is too high when used in large mass collection. As the number of instance is increased, it affects the execution time of SQWRL.

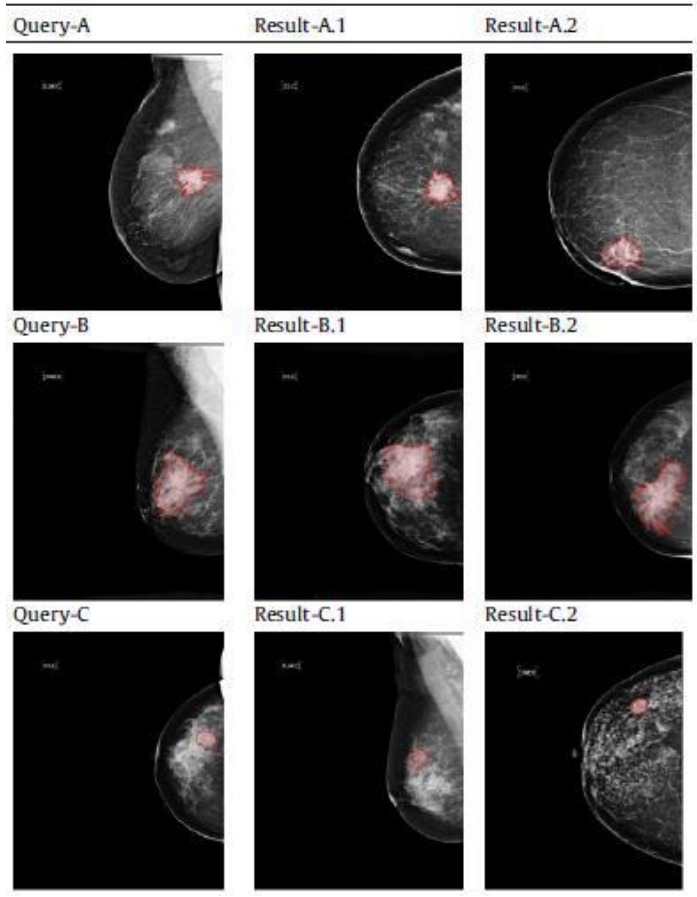

Figure 1. Sample mass queries with their results.

Image search, i.e., the recovery of similar cases in the database, is performed based on the proximity between the characteristics (mass) found in the views of mammograms. The Figure 1 shows some results obtained for queries. The author emphasizes that system time performance is too high when used in large mass collection. As the number of instance is increased, it affects the execution time of SQWRL.

\subsection{Ontology-Based Framework for Semantic Information Retrieval - OBFSIR}

In [15] is showed an ontology-based framework for semantic information retrieval, which highlights the existent difference between keyword-based information retrieval system and semantic information retrieval. The first one uses a keyword lists to represent the content of document. This type of keyword list is a description that does not say anything about semantic relationships between keywords. That complicates searches for similar words (synonyms). 
The main hypothesis of [15] is that the inclusion of conceptual knowledge in information retrieval process can contribute for the use of knowledge from a domain specific ontology to obtain better and more exact answers on a semantic basis, i.e. to compare concepts rather than words, that is, according to the authors, the major problems in current information retrieval systems [9], [33]- [43].

The proposed method automatically creates semantic metadata by using ontologically enhanced versions of information extraction methods. To this, information extraction (IE) techniques can substantially support automatic metadata generation. Therefore, start metadata generation with an IE step, after that, semantic indexing step is performed. It consists in collecting terms corresponding to all the words contained in the documents, observing the frequency of words to specify the document content. Finally, a query representation is performed. It aims at reducing the gap between user intention and system interpretations of queries and documents. To evaluate the proposal, breast cancer ontology was used for comparing information recovery (IR) based on keywords and ontology. The classical IR system, which is based on keywords, presents two problems: Noise (non pertinent documents returned in search results which contain the same keywords but in other contexts) and Silence (pertinent documents not returned in search results which contain synonyms concepts to keywords).

By using ontology in the IR system, search is automatically extended to include synonyms. For example, in a search for documents on "mastectomy", an onto-logy-based system would return also documents associated with "breast removal".

A novel feature of this system is that horizontal, vertical, and hybrid fragmentation rules about underlying schema that can be declared and used, increasing system's recall and improving performance. Kondylakis et al [24] highlight that system's performance is optimized by eliminating local subqueries and avoiding joins in the result composition plan that are certain to return empty results.

\subsection{Intelligent Tutoring System - ITS}

Maffon et al [27] presented an Intelligent Tutoring System (ITS) applied to teaching breast anatomy and pathology, more specifically breast cancer. ITS provides a didactic help to students and health professionals to understanding explanations and practical applications needed to this domain of knowledge. The use of Artificial Intelligence techniques gives ITS a great capacity to store knowledge about the learning virtual environments. These characteristics are used, on the scope of Education, to define which strategies and tactics can be used to get the best teaching process.

ITS is composed by four modules: Student, Domain, Tutor and Interface. To associate the medical vocabulary of anatomy female breast with multimedia content was developed ONTOMAMA ontology. The Domain Module includes all the elements needed to represent the knowledge as well as a mechanism for automatic information retrieval. ONTOMAMA is composed by four parts interconnected ontomama_main.owl, ontomama_anatomy.owl, ontomama_pathology.owl and ontomama_datatype.owl, with representatives of the medical knowledge of the pathologies. To achieve the goal this system has a questionnaire to be answer about name, sex, age and a questionnaire to Learning Styles. This input is created/activated the student profile and this respective value is inserted in the Ontology by ONTOMAMA. ONTOMAMA choose the respective media of the content supplied by Domain Mo-dule. Tutor Module shows on Interface the content adapted to student profile. Validation process of ITS is in progress, but shows promise.

\subsection{Nottingham Grading System - NGS}

The Nottingham modification of the Scarff-Bloom-Richardson grading system, also known as the Nottingham Grading System (NGS) [17], is a grading system recommended by various professional institutions, such as the World Health Organization (WHO), American Joint Committee on Cancer (AJCC), European Union (EU), and the Royal College of Pathologists (UK RCPath) [16] and [39].

NGS is a system used to classify and interpret content in a histopathological image, about breast cancer. For this, a specific ontology was created to represent the features found in each image and classify them as one type of cancer. The Table 1 describes the main features used by NGS to represent knowledge in histopathological image, comprising three components. The three component of the NGS criteria are: tubule formation, mitosis count, and nuclear pleomorphism score. Each criterion is valued in three scores $(1,2,3$ being associated to the most serious case), a tumor may get maximum score of 9 .

Table 1. Classification of NGS

\begin{tabular}{|c|c|c|c|}
\hline \multicolumn{4}{|c|}{ Grading Breast Cancers } \\
\hline \multicolumn{2}{|l|}{ Tubule Formation } & \multicolumn{2}{|l|}{ Mitotic Count } \\
\hline $\begin{array}{l}\text { Majotarity of } \\
\text { Tumor }(>75 \%)\end{array}$ & 1 & 0 - 9 Mitotes / $10 \mathrm{hpf}$ & 1 \\
\hline $\begin{array}{l}\text { Moderate Degree } \\
(10-75 \%)\end{array}$ & 2 & $\begin{array}{l}10-19 \text { Mitotes / } 10 \\
\text { hpf }\end{array}$ & 2 \\
\hline $\begin{array}{l}\text { Little or None } \\
(<10 \%)\end{array}$ & 3 & $\begin{array}{l}20 \text { or }>\text { Mitotes / } 10 \\
\text { hpf }\end{array}$ & 3 \\
\hline
\end{tabular}

\section{Grading Breast Cancers}

\begin{tabular}{|l|l|l|l|l|}
\hline \multicolumn{2}{|l|}{ Nuclear Pleomorphism } & & \multicolumn{2}{|l|}{ Combined Histologic Grade } \\
\cline { 1 - 2 } $\begin{array}{l}\text { Small Regular } \\
\text { Uniform Cells }\end{array}$ & 1 & Low Grade (I) & $3-5$ \\
\hline $\begin{array}{l}\text { Moderate Nuclear } \\
\text { Size and Variation }\end{array}$ & 2 & Intermediate Grade (II) & $6-7$ \\
\hline $\begin{array}{llll}\text { Marked Nuclear } \\
\text { Variation }\end{array}$ & 3 & High Grade (III) & $8-9$ \\
\hline
\end{tabular}

Images are processed by an image analysis algorithm, which highlights the features related to biological concepts, such as nuclei, mitosis and tubules. After this process, following semantic rules, images are classified using NGS providing a second opinion to the expert.

NGS is also applied in others works [[41][28][18][12][31]. According to Meriem and Yamina [28] articulated knowledge management capabilities with low-level image analysis modules can not only improve the design of the system but increase the performance of the system, as well [28]. NGS system shows robust to breast cancer classification presenting relevant results. However, its applications are exclusive to histopathological images which prevent their use for mammograms.

\subsection{Archetypes to identification and treatment process - AITP}

Serna et al. [35] present a system that uses ontology and inference rules to support decision making in the identification 
and treatment planning of breast pathologies. Beginning with adequate examination of patient, characteristics are identified to determine the stage of cancer. In medical practice the stage of breast cancer is defined by three principles: $\mathrm{T}$ (size of the primary tumor), $\mathrm{N}$ (involvement of the lymphatic nodes), $\mathrm{M}$ (metastasis to others locals) and their subsets. Table 2 shows these stages.

Ontology is created to represent the domain knowledge from the features obtained previously. Based on this representation inference rules will be created to identify cancer and possible treatments. These can be presented like: "If tumor is bigger than $5 \mathrm{~cm}$ it is considered T3 (rule 1), if there are more than 9 nodes infected N3 (rule 2), and the results of metastasis tests are negative (rule 3 ). With these results the diagnostic is a surgery cancer in stage IIIC (rule4)".

When cancer is detected inference rules define which treatment is necessary, duration and drugs to take in each case. For instance, considering the previous example, three different rules can be enumerated:

R1: Recommended Drug Treatment $\rightarrow$ Tamoxifen 40mg during 2 years.

R2: LymphNodes Recommended Treatment $\rightarrow$ Radiation to supravicular and/or internal mammary lymph nodes and removed auxiliary lymph nodes.

R3: Breast Recommended Treatment $\rightarrow$ modified radical mastectomy followed by radiation and lumpectomy plus radiation following chemotherapy to shrink a large single cancer.

Table 2. Stages of the breast cancer

\begin{tabular}{|c|c|c|}
\hline $\begin{array}{l}\text { T (Primary } \\
\text { Tumor) }\end{array}$ & $\begin{array}{l}\text { N (Lymphatic } \\
\text { Nodes) }\end{array}$ & $\begin{array}{l}\text { M (Presence of } \\
\text { Metastasis) }\end{array}$ \\
\hline $\begin{array}{l}\text { T0: There is no } \\
\text { evidence of tumor }\end{array}$ & $\begin{array}{l}\text { N0: There is no } \\
\text { lymphatic nodes } \\
\text { affected }\end{array}$ & \multirow{2}{*}{$\begin{array}{l}\text { M0: There is no } \\
\text { metastasis }\end{array}$} \\
\hline $\begin{array}{l}\text { T1: Tumor size is } \\
\text { less or equal than } 2 \\
\mathrm{~cm}\end{array}$ & $\begin{array}{l}\text { N1: Cancer has } \\
\text { spread from } 1 \text { to } 3 \\
\text { lymphatic nodes }\end{array}$ & \\
\hline $\begin{array}{l}\text { T2: Tumor size is } \\
\text { between } 2 \text { and } 5 \mathrm{~cm}\end{array}$ & $\begin{array}{l}\text { N2: Cancer has } \\
\text { spread from } 4 \text { to } 9 \\
\text { lymphatic nodes }\end{array}$ & \multirow{2}{*}{$\begin{array}{l}\text { M1: There is } \\
\text { metastasis, so the } \\
\text { cancer spreads to } \\
\text { near organs }\end{array}$} \\
\hline $\begin{array}{l}\text { T3: Tumor size is } \\
\text { bigger than } 5 \mathrm{~cm}\end{array}$ & $\begin{array}{l}\text { N3: Cancer has } \\
\text { spread to more than } \\
9 \text { lymphatic nodes }\end{array}$ & \\
\hline
\end{tabular}

Serna et al. highlight that it is important to say that the solution will be used to help medical doctors to make a decision on diagnostic and treatment. However, the final decision will always be, of course, a human decision.

\section{Summary}

Table 3 shows a summary of the main features of each of the discussed systems. From the enumerated advantages, it is possible to note the importance of the use of ontologies in different ways, such as information retrieval, searching, classification, interpretation, annotation, and others.

Table 3. Literature review summary

\begin{tabular}{|l|c|c|c|c|}
\hline System & $\begin{array}{c}\text { Main } \\
\text { Purpose }\end{array}$ & Advantages & Drawbacks & Ontology \\
\hline
\end{tabular}

\begin{tabular}{|c|c|c|c|c|}
\hline MIAKT & $\begin{array}{l}\text { Support } \\
\text { decision to } \\
\text { screening, } \\
\text { diagnosis } \\
\text { and } \\
\text { treatment }\end{array}$ & $\begin{array}{l}\text { Can be used } \\
\text { in } \\
\text { mammograp } \\
\text { hy, MRI and } \\
\text { histopatholo- } \\
\text { gical image }\end{array}$ & $\begin{array}{l}\text { Classificati- } \\
\text { on accuracy } \\
\text { is limited by } \\
\text { data source }\end{array}$ & BCIO \\
\hline Aquest & $\begin{array}{l}\text { Semantic } \\
\text { search and } \\
\text { queries }\end{array}$ & $\begin{array}{c}\text { Facilitates } \\
\text { search from a } \\
\text { web system } \\
\text { and allows } \\
\text { using a } \\
\text { different } \\
\text { ontologies }\end{array}$ & $\begin{array}{l}\text { Pre-defined } \\
\text { questions not } \\
\text { allowing } \\
\text { changes }\end{array}$ & $\begin{array}{c}\text { Breast } \\
\text { Cancer } \\
\text { Onto }\end{array}$ \\
\hline INDIAM & $\begin{array}{l}\text { Mammo- } \\
\text { grams } \\
\text { interpretati } \\
\text { on and } \\
\text { diagnosis }\end{array}$ & \begin{tabular}{|c|} 
To guide \\
students and \\
radiologist to \\
interpret a \\
mammograp \\
hy \\
\end{tabular} & $\begin{array}{c}\text { Have a } \\
\text { limited } \\
\text { vocabulary }\end{array}$ & $\begin{array}{c}\text { Breast } \\
\text { Cancer } \\
\text { Onto }\end{array}$ \\
\hline MAT & $\begin{array}{c}\text { Mammogra } \\
\text { phy } \\
\text { annotation }\end{array}$ & $\begin{array}{l}\text { Allows the } \\
\text { visualization } \\
\text { of the image } \\
\text { while occur } \\
\text { markup }\end{array}$ & $\begin{array}{c}\text { Time } \\
\text { performance } \\
\text { is too poor in } \\
\text { a large mass } \\
\text { collection. } \\
\end{array}$ & MAO \\
\hline OBSSIR & $\begin{array}{c}\text { Information } \\
\text { Retrieval }\end{array}$ & $\begin{array}{c}\text { Semantic } \\
\text { relationships } \\
\text { of keywords, } \\
\text { not keyword } \\
\text { list }\end{array}$ & $\begin{array}{c}\text { Can } \\
\text { generalize } \\
\text { too much in } \\
\text { some cases }\end{array}$ & $\begin{array}{l}\text { Specific } \\
\text { Ontology }\end{array}$ \\
\hline ITS & $\begin{array}{l}\text { Teaching- } \\
\text { learning } \\
\text { and sharing } \\
\text { information }\end{array}$ & $\begin{array}{l}\text { Uses AI to } \\
\text { gives ITS a } \\
\text { great } \\
\text { capacity to } \\
\text { store } \\
\text { knowledge } \\
\text { about the } \\
\text { learning } \\
\text { virtual } \\
\text { environments }\end{array}$ & $\begin{array}{l}\text { Was not } \\
\text { actually } \\
\text { tested }\end{array}$ & $\begin{array}{l}\text { Onto } \\
\text { Mama }\end{array}$ \\
\hline NGS & $\begin{array}{c}\text { Classificati } \\
\text { on and } \\
\text { interpretati } \\
\text { on }\end{array}$ & $\begin{array}{l}\text { Histopatholo } \\
\text { gical criteria } \\
\text { for } \\
\text { classification }\end{array}$ & $\begin{array}{c}\text { Histopatholo } \\
\text { gical images } \\
\text { only }\end{array}$ & $\begin{array}{l}\text { Specific } \\
\text { Ontology }\end{array}$ \\
\hline AITP & $\begin{array}{c}\text { Identification } \\
\quad \text { and } \\
\text { treatment of } \\
\text { breast cancer }\end{array}$ & $\begin{array}{l}\text { Helps doctors } \\
\text { to identify } \\
\text { treatment to be } \\
\text { follow in each } \\
\text { case }\end{array}$ & $\begin{array}{c}\text { Needs all } \\
\text { features of the } \\
\text { condition } \\
\text { given } \\
\text { manually to } \\
\text { indicate step to } \\
\text { be followed }\end{array}$ & $\begin{array}{l}\text { Specific } \\
\text { Ontology }\end{array}$ \\
\hline
\end{tabular}

However, we can note from the drawbacks listed, that many ontology-based systems do not satisfy the researchers ambitions with respect to the detection of breast cancer. Systems still present slow response time, limited vocabulary and classification, so that these systems are not used in practical as it should be.

\section{Conclusion}

In this work, we discuss some systems that use ontology for better manipulating information related to cancer and other breast pathologies. The importance of ontologies in this domain area is undeniable, due contributions such as (a) improving the capacity of sharing the knowledge of radiologists; (b) allowing the retrieval of similar cases in the process of organizing and storage information; (c) explicit definitions inherent in the 
medical field; (d) analysis of shared knowledge; and (e) enabling data reuse.

A main challenge in breast cancer treatment is to find the cancer before it presents symptoms; the earlier the cancer is detected, better chances cancer patients have for cure and treatment. The limitation of human observations is a drawback: $10-30 \%$ of the cases are missed during routine screening [11]. With the advances in systems that use ontologies, health professionals have the chance to achieve better results for their diagnosis in current cases, and prognosis of the new ones.

One benefit brought by the use of ontology is the possibility of separating the domain knowledge of the expert in question for their practical use. Thus, the professionals who develop systems do not need to be experts in the medical field, since this knowledge is already stored. The great relevance of systems using ontology has allowed the support of decision making for health professionals. Therefore, it is necessary that the information is stored in a coherent and organized way to maximize its usability.

Additionally, other benefit brought by the use of ontologies in the medicine field is the possibility of organizing and structuring medical reports [1][21][25]. This is useful to represent the knowledge, improving the information transmission and facilitating the search of clinical data with the standardization of the terms to fill this document. In Brazil, there is a system for allowing the creation of standardized mammography reports, the Brazilian Information System of Breast Cancer - SISMAMA - (in Portuguese, Sistema de Informação do Câncer de Mama). SISMAMA was developed by the Brazilian Cancer Institute [6], in association with the Informatics Department of the Brazilian Health System, to support Brazilians physicians in the diagnostic control of breast cancer. That system has brought several benefits to radiologist doctors, and ontologies can be used to structure others radiological reports

Moreover, it is fundamental that the proposed system be easy to understand and to manipulate by health professionals, favoring their concisely use. Obviously, systems do not seek to entirely replace physicians or radiologist, but may help in cases of doubt, making simpler decision to be made.

\section{ACKNOWLEDGMENTS}

We gratefully acknowledge the financial support of CAPPES.

\section{References}

[1] Barbosa, F., Maciel, L. M. Z., Vieira, E. M., Marques, P. M. A., Jr., J. E. and Muglia, V. F. 2010. Radiological reports: A comparison between the transmission eficiency of information in free text and in structured reports. Clinic Science 65, 1, 15- 21 .

[2] Barcelos, L. P., Santos, R. S., Lima, P.S., de Paula, N. M A. and Reis, A. S. 2010. Os Genes BRCA1 e BRCA2 e Suas Relações Genéticas na Predisposição aos Carcinomas Mamários Hereditários e Esporádicos. Estudos (Goiânia. Online), pp. v. 37, p. 837-850..

[3] Boaventura, R. S. 2009. Um Sistema de Consulta Orientado por Ontologia Para Auxiliar Estudantes na Interpretação de Mamogramas e Diagnóstico de Câncer de Mama Via Web. Revista CEPPG. 20, p. 182 - 195.
[4] Bodenreider O. 2004. The Unified Medical Language System (UMLS): integrating biomedical terminology. Nucleic Acids Res 2004, 32:D267-270.

[5] Boyd, N. F., Byng, J. W., Jong, R. A., Fishell, E. K., Little, L. E., Miller, A. B., Lockwood, G. A., Tritchler, D. L. and Yaffe, M. J.: Quantitative classification of mammographic densities and breast cancer risk. J Natl Cancer Inst. 87:670-5: 1995.

[6] Brazilian Cancer Institute, I. Available at: http://www.inca.gov.br

[7] Breitman, K. 2005. Web Semântica, a Internet do Futuro. 1. s.l.: LTC - Livros Técnicos Científicos SA.

[8] Bulu, H., Alpkocak, A. and Balci, P. 2012. Ontologybased mammography annotation and Case-based Retrieval of breast masses. Elsevier. Expert Systems with Application.

[9] Bulu, H., Alpkocak, A. and Balci, P. 2013. Uncertainty Modeling for Ontology-based Mammography Annotation with Intelligent BI-RADS Scoring. Computers in Biology and Medicine, Vol.43, Issue.4, pp.301-3011.

[10] Cancer Org. Available at: http://www.cancer.org/breastcancer/

[11] Cheng, H., Cai, X., Chen, X., Hu, L. and Lou, X. 2003. Computer-Aided Detection and Classification of Microcalcifications in Mammograms: A Survey. Pattern Recognition, 36 (12), pp 2967-2991.

[12] Dalton, L. W. Pinder, S. E. Elston, C. E. Ellis, I. O. Page, D. L Dupont, W. D. and Blamey, R. W. 2000. Histologic grading of breast cancer: linkage of patient outcome with level of pathologist agreement. Mod Pathol, Vol. 13, pp. 730-5.

[13] Dasmahapatra, S. and O'Hara. 2006. Interpretations of Ontologies for Breast Cancer. Interpretations of Ontologies for Breast Cancer. TripleC, 4, (2),293-303. Kieron.

[14] Dasmahapatra, S., Dupplaw, D., Hu, B., Lewis, H., Lewis, P. and Shadbolt, N. 2004. Facilitating Multi-Disciplinary Knowledge-Based Support for Breast Cancer Screening. Intl. Journal of Healthcare Technology and Management .

[15] Dridi, O. and Ahmed, B. M. 2008. Building an OntologyBased Framework for Semantic Information Retrieval: Application to Breast Cancer. In: 3rd Intern. Conf. on Information and Communication Technologies: from Theory to applications. Damascus: ICTTA, pp. 1-6.

[16] Ellis, I. O. 2005. Pathology Reporting of Breast Disease: A Joint Document Incorporating the Third Edition of the NHS Breast Screening Programme's Guidelines for Pathology Reporting in Breast Cancer Screening and the Second Edition of The Royal College of Pathologists' Minimum Dataset for Breast Cancer Histopathology. Sheffi eld.; NHS Cancer Screening Programmes and The Royal College of Pathologists; January 2005.

[17] Elston, C. W. and Ellis, I. O. 1991. Pathological Prognostic Factors In Breast Cancer. The Value Of Histological Grade In Breast Cancer: Experience From A Large Study With Long-Term Follow-Up. Histopathology, 19:403-410

[18] Genestie, C. Zafrani, B. Asselain, B. Fourquet, A. Rozan, S. Validire, P. Vincent-Salomon, A. and Sastre-Garau, X. 1998. Comparison of the prognostic value of ScarffBloom-Richardson and Nottingham histological grades in a series of 825 cases of breast cancer: major importance of 
the mitotic count as a component of both grading systems. Anticancer Res, Vol. 18, pp. 571-6.

[19] Guliato, D., Boaventura, R., Maia, M. A., Rangayyan, R., Simedo, M. and Macedo, T. A. A. 2009. INDIAM an eLearning System for the Interpretation of Mammograms. Journal of Digital Imaging, v. 22, p. 405-420.

[20] Hu, B., Dasmahapatra S, Lewis P. and Shadbolt N. 2003. Ontology-based medical image annotation with description logics. IEEE ICTAI'03, November 3--5, pp.77--82.

[21] Hussein, R., Engelmann, U. Schroeter, A. and Meinzer, H. 2004. Dicom Structured Reporting. part 1: overview and characteristics. RadioGraphics 24, pp, 981- 986.

[22] Hwang K., H., Lee, H. and Choi, D. 2012. Medical image retrieval: Past and present. Health Information Research 18(1) 3-9.

[23] INCA. National Cancer Institute / Healthy Ministry, 2013. Estimative 2014 (In Portuguese).

[24] Kondylakis, H., Analyti, A. and Plexousakis, D. 2007 Quete: Ontology-Based Query System for Distributed Sources. ADBIS, volume 4690 Lecture Notes in Computer Science, pp. 359-375. Springer.

[25] Langlotz, C. and Meininger, L. Enhancing the Expressiveness and Usability of Structured Image Reporting Systems. Procedings AMIA annu Fall Sym, pp, $467-471$.

[26] Li, S., Ting, N. S., Zheng, L. and Chen, P. 2000. Functional link of BRCA1 and ataxia telangiectasia gene product in DNA damage response. Nature, n. 406, p.210215.

[27] Maffon, H. P., Melo, J. S., Morais, T. A., Klavdianos, P. B., Brasil, L. M., Amaral, T. L. and Curilem, G. M. 2013. Architecture of an Intelligent Tutoring System Applied to the Breast Cancer Based on Ontology, Artificial Neural Networks and Expert Systems ACHI 2013: The Sixth International Conference on Advances in ComputerHuman Interactions.

[28] Meriem, B. and Yamina, T. 2012. Interpretation breast cancer imaging by using ontology. Cyber Journals: Multidisciplinary Journals in Science and Technology. Journal of Selected Areas in Bioengineering (JSAB). p. March Edition.

[29] Mustafa, J., Khan, S and Latif K. 2008. Ontology based semantic information retrieval. Intelligent Systems. IS'08. 4th International IEEE Conference 3, 22-14.

[30] Pickler, M. E. V. 2007. Web Semântica: Ontologias como Ferramentas de Representação do Conhecimento Belo Horizonte: v. 12, n. 1. Perspectiva em Ciência da Informação. pp. 65-83.

[31] Rakha, E. A., Reis-Filho, J. S., Baehner, F., Dabbs, D. J., Decker, T., Eusebi, V. Fox, S. B., Ichihara, S., Jacquemier, J., Lakhani, S. R., Palacios, J., Richardson, A. L., Schnitt, S. J., Schmitt, F. C., Tan, P. H., Tse, G. M., Badve, S. and Ellis, I. O. 2010. Breast cancer prognostic classification in the molecular era: the role of histological grade. 4, Breast Cancer Research, Vol. 12, p. 207, 2010.
[32] Rosse, C. and Mejino, J.L.F. 2003. The Foundational Model of Anatomy ontology. In Anatomy Ontologies for Bioinformatics (eds. Burger, A. et al.) (Springer, New York, in the press).

[33] Rubin, D.L. 2008. Creating and curating a terminology for radiology: ontology modeling and analysis. J Digit Imaging, 21:355-62.

[34] Serna, A., Gerrikagoitia, J. K. and Huerga, I. 2009. Supporting Clinical Processes with Semantic Web Technologies: A Case in Breast Cancer Treatment. Inderscience publishers, International Journal of Metadata, Semantics and Ontologies (IJMSO), Vol. 5, pp. 309-320.

[35] Serna, A., Gerrikagoitia, J. K., Huerga, I. Zumalakarregi, J. A. and Pijoan, J. I. 2009.Archetypes and Ontologies to Facilitate the Breast Cancer Identification and Treatment Process. 1st Symposium on Healthcare Systems Interoperability. Madrid, Spain.

[36] Shadbolt, N., Lewis, P., Dasmahapatra, S., Dupplaw, D., Hu, B. and Lewis, H. 2004. MIAKT: Combining grid and web services for collaborative medical decision making. In Proceedings of AHM2004 UK e Science All Hands Meeting .

[37] Shehzad, A., Ngo, H. Q, Pham, K. A. and Lee, S. Y. 2004. Formal Modeling in Context Aware Systems. Proceedings of the First International Workshop on Modeling and Retrieval of Context.

[38] SNOMED SNOMED CT, http://www.nlm.nih.gov.research/umls/Snomed.snomed_m ain.html

[39] Tavassoli, F. A. and Devilee, P. 2003. World Health Organization classification of tumours. In Pathology and Genetics Tumours of the Breast and Female Genital Organs. Lyon: IARC Press; 19-23.

[40] The Gene Ontology Consortium: Gene Ontology: tool for the unification of biology. Nature Genet 2000, 25:25-29.

[41] Tutac, A. E. Racoceanu, D. Putti, T. Xiong, W. Leow, W. K. and Cretu, V. 2008. Knowledge-Guided Semantic Indexing of Breast Cancer Histopathology Images. Int Conf. on Biomedical Engineering and Informatics (BMEI). 5 de 2008, pp. 27-30.

[42] Uschold, M. and Gruninger, M. 1996. Principles methods and applications. Knowledge Engeneering Review, pp. 11:93-136.

[43] Vallet, D., Fernández, M. and Castells, P. 2005. An Ontology-Based Information Retrieval Model. Second European Semantic Web Conference, ESWC 2005, Heraklion, Crete, Greece, pp 455-470.

[44] VisualLab avaliable in: http://visual.ic.uff.br.

[45] Wang, X.H., Zhang, D.Q., Gu, T. and Pung, H.K. 2004. Ontology based context modeling and reasoning using OWL. Proceedings of 2nd IEEE Conf. Pervasive Computing and Communications (PerCom 2004), Workshop on Context Modeling and Reasoning. pp 18-22. 